\title{
Effect of solution treatment on the microstructure and mechanical properties of Ti-6Al-6Mo hot-rolled alloy
}

\author{
Alfirano $^{1}$, S. S. Friandani ${ }^{1}$, and C. Sutowo ${ }^{2}$ \\ ${ }^{1}$ Department of Metallurgical Engineering, University of Sultan Ageng Tirtayasa, \\ J1. Jenderal Sudirman KM 3 Cilegon 42435, Indonesia \\ Phone: +62254376712; Fax: +62254376712 \\ *Email: alfirano@untirta.ac.id \\ ${ }^{2}$ Indonesian Institute of Sciences-LIPI, Jl. Raya Puspitek, \\ Tangerang Selatan 15413, Indonesia
}

\begin{abstract}
Titanium and its alloys are commonly used in biomedical applications because of their unique combination of good hot workability, high specific strength and good corrosion resistance. In this study, elastic modulus, hardness and the effects of solution treatment on microstructures and mechanical properties of Ti-6Al-6Mo hot-treated alloy were investigated using Optical microscopy (OM), X-ray Diffractometry (XRD), Scanning electron microscopy (SEM), ultrasonic testing and hardness testing. Previously, the sampels were hotrolled at $900^{\circ} \mathrm{C}$ for 1 hour with a total reduction of $50 \%$, and then followed by air cooling. The samples were carried out solution treatment for $1 \mathrm{~h}$ at $850^{\circ} \mathrm{C}$ and $950^{\circ} \mathrm{C}$, followed by water cooling and at temperature of $1050^{\circ} \mathrm{C}$ with water and air cooling. The results indicate that the hardness of the Ti-6Al-6Mo alloy increased with the increasing of solution treatment temperature on the water cooling, while the elastic modulus was decreased. The lowest elasticity modulus value and the highest hardness, 125.4 GPa and 46.3 HRC were obtained at $1050^{\circ} \mathrm{C}$ with equiaxed micro structure and $\beta^{\prime}$ precipitate. XRD analysis exhibited the presence of $\alpha$ and $\beta$ phases in Ti-6Al-6Mo alloys after solution treatment. Based on the relative intensity of XRD strongest peak analysis, the $\alpha$ phase intensity decreases with the increasing of solution treatment temperature. This phenomenon causes the decreasing of elasticity modulus value with the rising of solution treatment temperature on water cooling medium.
\end{abstract}

Keywords: Ti-Al-Mo; solution treatment; modulus elastic; $\alpha$ phase, $\beta$ phase.

\section{INTRODUCTION}

Titanium and its alloys are receiving increasing research attention due to their excellence in specific strength, elastic modulus, corrosion resistance and biocompatibility compared to another metallic biomaterial alloys [1-7]. Besides being used for orthopaedic and dental in biomedical applications, titanium alloys as well as cobalt and stainless steel are also being used as materials for cardiovascular stent [8-11]. As one type of titanium alloys, the $\alpha+\beta$ alloys are widely used because of the various microstructures and mechanical properties can 
be achieved by elements alloying and thermo-mechanical treatments. Ti6Al64V is one type of $\alpha+\beta$ alloys that is commercially known as the main titanium alloys [12-16]. Because the toxicity of Vanadium has been reported, Vanadium-free titanium alloys like $\mathrm{Ti}-6 \mathrm{Al}-7 \mathrm{Nb}$ and $\mathrm{Ti}-5 \mathrm{Al}-2.5 \mathrm{Fe}$ have been recently developed by several researchers $[17,18]$. Moreover, metal elements such as Al, V and Fe have higher cytotoxicity based on Kawahara's study [19]. Similarly, because of the special mechanical properties such as super elasticity and shape memory effect, TiNi alloys have been clinical applied for years [20-22]. However, lately Ni Nickel is classified as a toxic and incompatible element [23,24].

Recently, two types of $\alpha+\beta$ type Ti-6Al-6Mo alloys are developed. This alloy has good hot workability, hardness, strength and good corrosion resistance. Molybdenum as substitute of Vanadium serves as a $\beta$ stabilizer element which can increase strength and decrease the elastic modulus of the alloy [25]. In order to observel the microstructure of titanium alloys, most of the studies in $\alpha+\beta$ type alloy focus on the formation of the primary $\alpha$ phase. Hot rolling accompanied with post heat treatment is the most effective method. This method can be used for strengthening of alpha-beta titanium alloys and to refine its morphology [26,27]. The mechanical properties of Ti $\alpha+\beta$ type alloys can be controlled by solution treatment [28-30]. Solution treatment is the most common heat treatment method used to obtain Ti alloys with low elastic modulus [31-33]. Important parameters in the solution treatment process include temperature and cooling solution. From previous study, solution treatment temperatures affect the $\alpha$ phase volume fractions and affecting $\alpha$ lamellar phase width [34-36]. Hot deformation also affects the microstructures and mechanical properties. The increased percentage reduction of hot rolling produces elongated grain fibres containing fine-equiaxed sub grains [37-39]. Sub-grain size increases with increasing deformation temperatures and equiaxed fine grains formed with a heating temperature of 973 $\mathrm{K}$. Tensile strength increases with increasing percentage reduction in hot rolling process [40,41]. An $\alpha+\beta$ type titanium alloys is the most widely used for medical application. The most important problem of this alloy is having a high elastic modulus. So that its use is replaced by $\beta$ type titanium alloys. A $\beta$ type titanium alloys that have the lowest elastic modulus are usually produced by adding a $\beta$ phase-stabilizer elements. In this study, a solution treatment of alloy $\alpha+\beta$ type alloy is carried out to reduce the elastic modulus. Ti6Al-6Mo alloy is studied to determine the effect of solution treatment on the microstructure and mechanical properties after deformation in $\alpha+\beta$ region. It is expected that solution treatments can reduce the elastic modulus as well as by addition a $\beta$ stabilizer element to the titanium alloy.

\section{METHODS AND MATERIALS}

Table 1 shows the chemical composition of the alloy used in this study. Ingots of the alloy were re-melted eight times in order to get chemical homogeneity.

Table 1. Chemical composition of the alloy (\% wt).

\begin{tabular}{ccccc}
\hline $\mathrm{Al}$ & Mo & $\mathrm{Fe}$ & $\mathrm{Cr}$ & $\mathrm{Ti}$ \\
\hline 5.76 & 5.10 & 0.067 & 0.13 & balance \\
\hline
\end{tabular}


Plates with a thickness of $10 \mathrm{~mm}$ cut from the ingots were homogenized (HM) at $900^{\circ} \mathrm{C}$ for $1 \mathrm{~h}$ in an argon (Ar) gas atmosphere, followed by furnace cooling. Then, the plates were hot-deformed at $900^{\circ} \mathrm{C}$ until $50 \%$ reduction. Hot-deformed alloy were subjected to solution treatment at $850^{\circ} \mathrm{C}, 900^{\circ} \mathrm{C}$ and $1050^{\circ} \mathrm{C}$ for $1 \mathrm{~h}$ in an argon gas atmosphere, followed by Water Cooling (WC); $850^{\circ} \mathrm{C}, 900^{\circ} \mathrm{C}$ and $1050^{\circ} \mathrm{C}$ and Air Cooling (AC); $1050^{\circ} \mathrm{C}$. The surfaces of the specimens were mechanically ground with emery paper and polished with alumina paste to a mirror finish and etched in Kroll solution (85\% distilled water, $10 \% \mathrm{HF}$ dan $5 \% \mathrm{HNO}_{3}$ ). An optical microscope and a scanning electron microscope were used to observe the microstructures of alloy. An energy dispersive X-ray spectrometer was used for the compositional analysis of the microstructures. The phases of the heat-treated alloy were identified using X-ray diffraction and the XRD patterns were obtained by $\mathrm{Cu} \mathrm{K} \alpha$ radiation. The hardness was determined by Rockwell $\mathrm{C}$ hardness tester with an applied load of $150 \mathrm{kgf}$ with six measurements for each sample. Ultrasonic tests were performed on hot-rolled alloy before and after solution treatment to determine the elastic modulus $(\mathrm{E})$ of the alloy using the thickness gage of DM4 DL and DA301 probe. Based on the ultrasonic test, ultrasonic longitudinal velocities and shear wave velocities will be obtained. The relationship between ultrasonic longitudinal velocities $\left(\mathrm{V}_{\mathrm{L}}\right)$ and shear wave velocities (VT) with elastic modulus values is shown in Eqn. (1) and the relationship between ultrasonic longitudinal velocities $\left(V_{L}\right)$ and shear wave velocities $\left(V_{T}\right)$ with Poisson ratio $(\sigma)$ is shown in Eqn. (2) [42].

$$
\begin{array}{r}
E=\frac{\rho V_{T}^{2}\left(3 V_{L}^{2}-4 V_{T}^{2}\right)}{V_{L}^{2}-V_{T}^{2}} \\
\frac{V_{T}}{V_{L}}=\sqrt{\frac{1-2 \sigma}{2(1-2 \sigma)}}
\end{array}
$$

\section{RESULTS AND DISCUSSIONS}

In Figure 1(a), the microstructure of the Ti-6Al-6Mo as-cast alloy was a Widmanstätten type, consisting of two phases, $\alpha$ and $\beta$. Widmanstätten type structure was a microstructure with unequal $\alpha$-phase growth direction. The microstructure of the Ti-6Al-6Mo homogenized alloy was a lamellar microstructure with $\alpha$-phase with plate-like morphology formed at the $\beta$ prior$\beta$ grain boundaries, as shown in Figure 1(b). The lamellar microstructure was obtained as a result of air cooling from the $\beta$ phase (solid solution) to $(\alpha+\beta)$ phase. The transformation of $\beta$ phase into $\alpha$ phase begins with the formation of nuclei at the $\beta$ prior grain boundary. The microstructure of Ti-6Al-6Mo hot-rolled alloy (perpendicular from rolling direction) was the $\alpha$ plate-like deformed phase in the $(\alpha+\beta)$ phase matrix, as shown on Figure 1(c).

The microstructure of Ti-6Al-6Mo of alloy solution treated resulted at $850^{\circ} \mathrm{C} / \mathrm{Water}$ Quenching (WQ) shows the existence of $\alpha$ phase with plate-like shape which has elongated during hot rolling in $(\alpha+\beta)$ phase matrix (Figure 2(a)). Solution treatment performed at $950^{\circ} \mathrm{C}$ WQ reduced the number and also increase the size of $\alpha$-plate-like phase in the $\alpha+\beta$ matrix as well as the formation of $\beta$-phase precipitate (Figure 2(b)). In the water quenched and air-cooled specimens, when the temperature was raised from $850^{\circ} \mathrm{C}$ to $950^{\circ} \mathrm{C}$, it tends to decrease the volume fraction of primary a and modify the matrix morphology. 

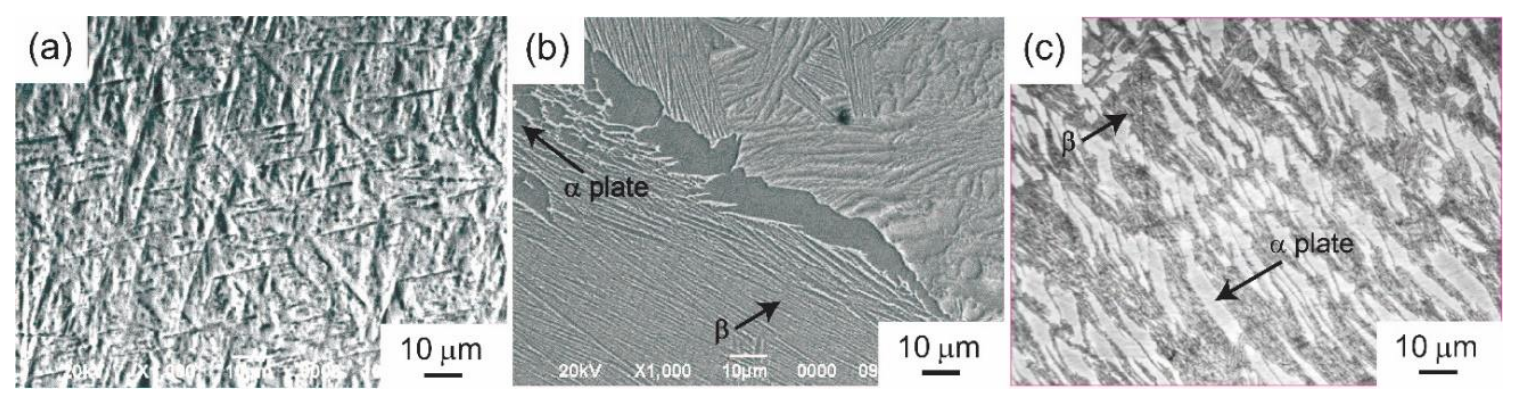

Figure 1. SEM images of Ti-6Al-6Mo (a) as-cast (b) homogenized and (c) hot-rolled alloy.

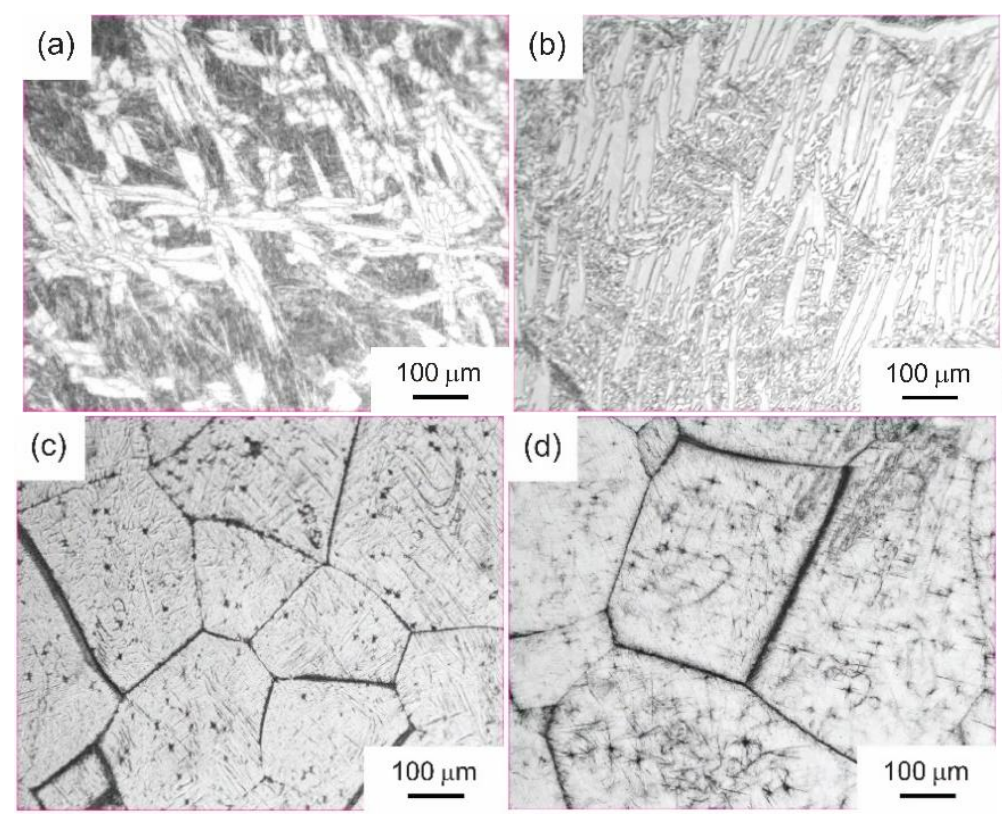

Figure 2. Optical microscope images of Ti-6Al-6Mo alloy after solution treatment (a) $850^{\circ} \mathrm{C} / \mathrm{WQ}$, (b) $950^{\circ} \mathrm{C} / \mathrm{WQ}$, (c) $1050^{\circ} \mathrm{C} / \mathrm{WQ}$ and (d) $1050^{\circ} \mathrm{C} / \mathrm{AC}$.

Borradaile et.al. [34] confirmed that both solution treatment temperature and the cooling rate from the solutionizing temperature determine the primary a volume fraction matrix. Solution treatment at $1050^{\circ} \mathrm{C} / \mathrm{WQ}$ gives an equiaxed microstructure of $\beta$ retained and $\alpha$ matrix (Figure $2(\mathrm{c})$ ). The $\beta$ phase appears as a precipitate along the grain boundary. Meanwhile, solution treatment at $1050^{\circ} \mathrm{C} /$ Air Cooling (AC), $\beta$ phase formed along the grain boundaries and tends to be uniformly arranged in the $\beta$ retained and $\alpha$ matrix (Figure 2(d)).

Figure 3 shows the XRD pattern of before and after solution treatment found the existence of peak shifting in each process. This shifting occurs due to the element of interstitial and substitution on the crystal structure that changes the parameters of the crystal lattice. The diffraction peaks indicate the presence of $\alpha$ and $\beta$ phases with the relative intensity of each phase shown in Figure 4, obtained from the calculation of the highest diffraction peak ratios of each phase. The highest intensity of $\alpha$ phase at temperature of $850^{\circ} \mathrm{C} / \mathrm{WQ}$ is $47.41 \%$, because the heating temperature is still under $\beta$-transus, so $\alpha$ phase has not passed allotropic transformation into $\beta$ phase yet. 


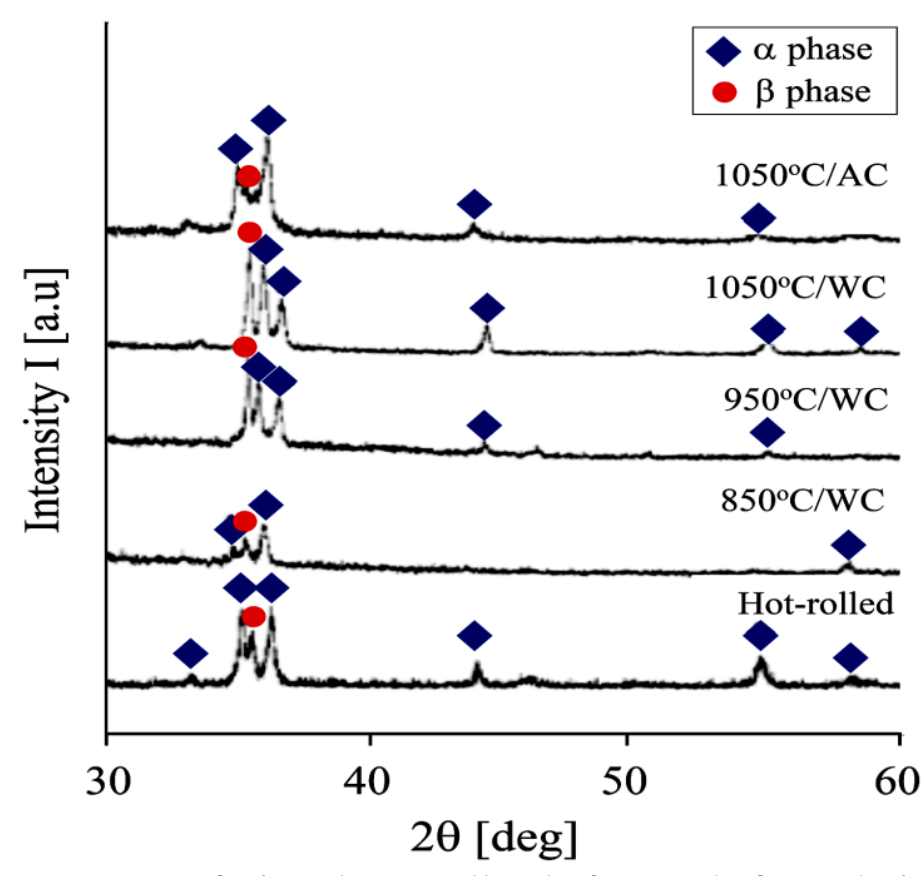

Figure 3. XRD patterns of Ti-6Al-6Mo alloy before and after solution treatment.

The intensity of $\alpha$ phase decreases with raising solution treatment temperature, with increasing solution treatment temperature, the more $\alpha$ phases that undergo allotropic transformation into $\beta$ phase when heating. The highest intensity of $\beta$-retained phase was obtained at solution temperature of $1050^{\circ} \mathrm{C} / \mathrm{WQ}$, which was $67.08 \%$. Increasing solution treatment temperature produce more $\alpha$ phases which transformed into $\beta$ phase. This is agreed with the results of EDS testing in which the increase in the number of phases $\beta$ was indicated by the presence of Mo in precipitates, as shown in Figure 5. The composition of Ti, Al, and Mo on precipitate was 90.1, 3.38, and 6.52 (in mass \%), respectively. Mo is a $\beta$ phase stabilizer. With high solution temperature and rapid cooling, it did not give enough time for $\beta$ phase to transform into $\alpha$ phase. 


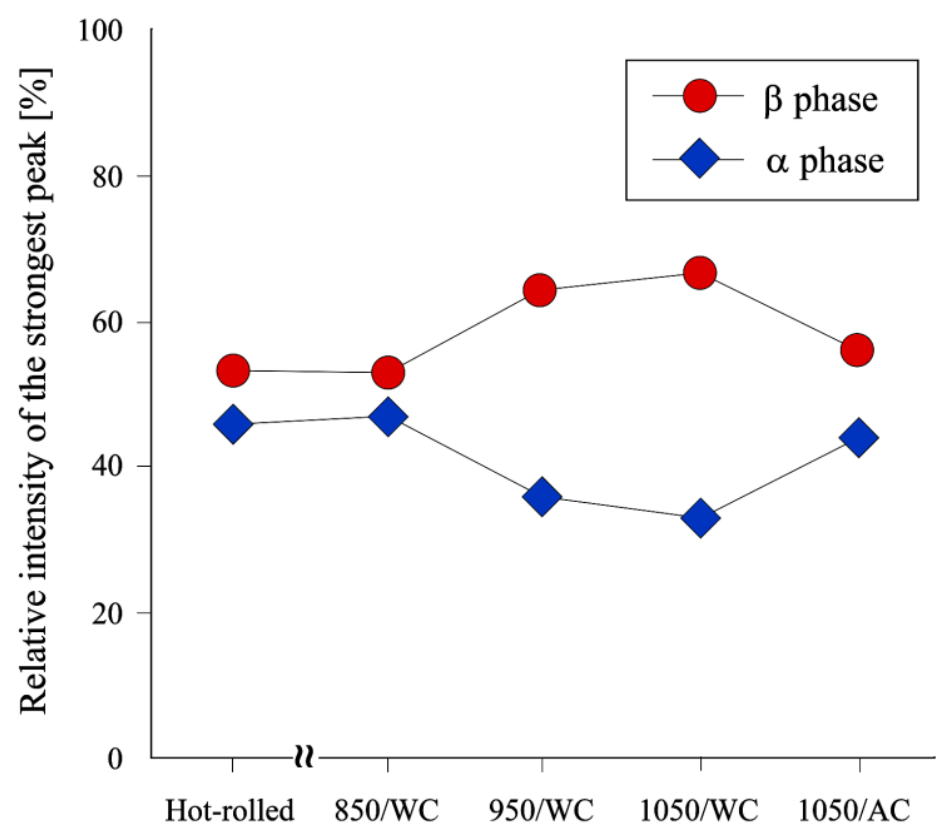

Figure 4. Relative intensities of the strongest peaks in the XRD patterns in the Ti-6Al-6Mo alloy before and after solution treatment.

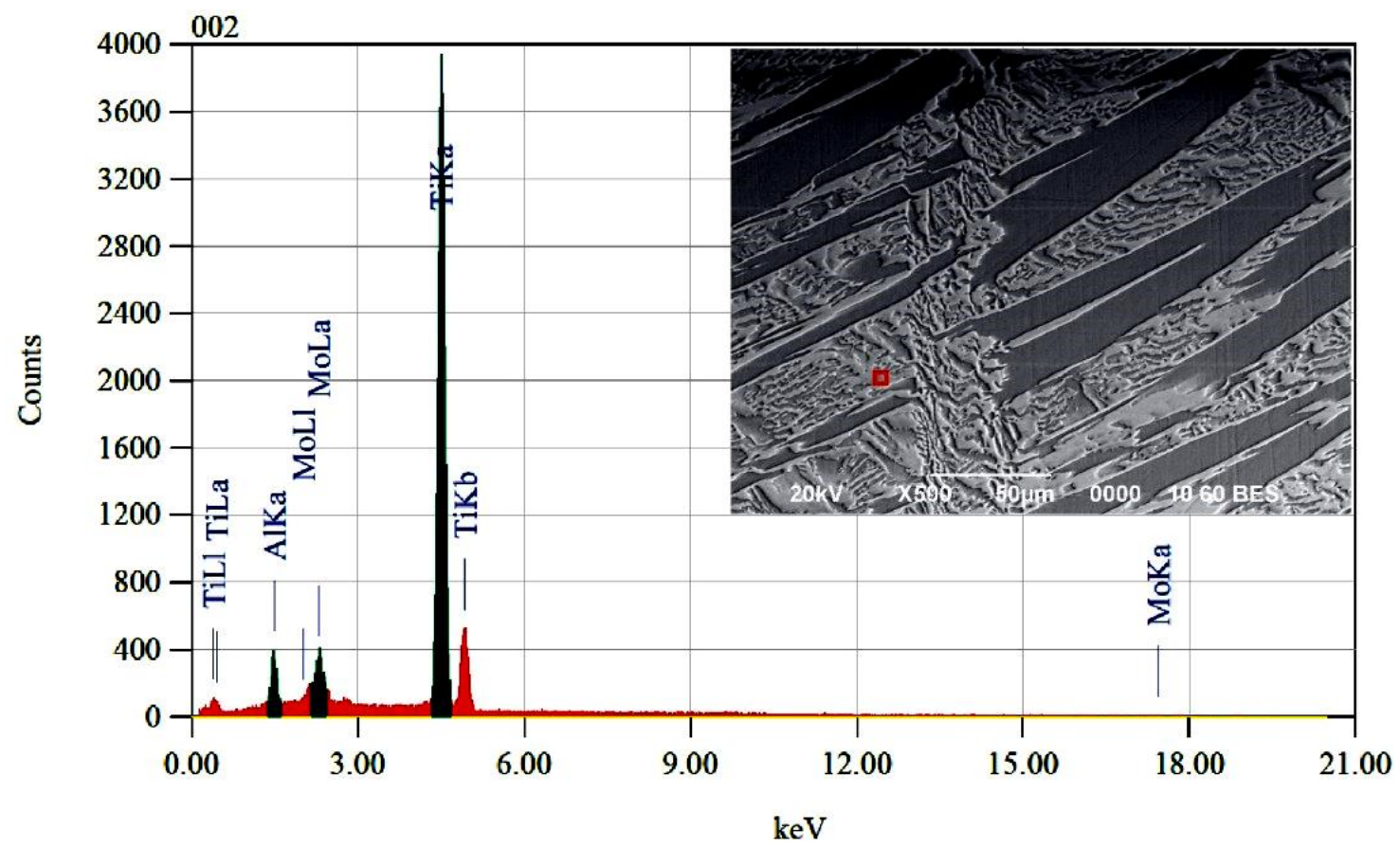

Figure 5. EDS analysis of Ti-6Al-6Mo alloy after solution treatment of $950^{\circ} \mathrm{C} / \mathrm{WQ}$. 


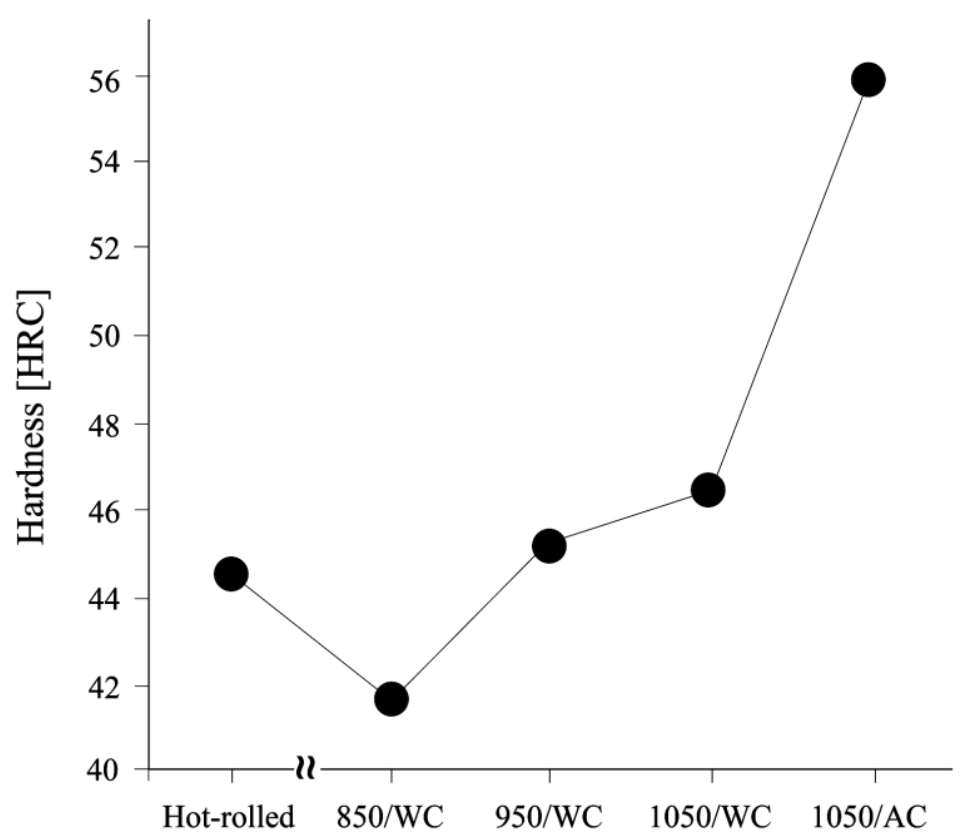

Figure 6. Effect of solution treatment on the hardness of Ti-6Al-6Mo alloy.

The hardness of $\alpha$ phase is higher than that of the $\beta$ phase [43], meanwhile $\beta$ phase has a higher hardness than the $\alpha^{\prime}$ and $\alpha^{\prime \prime}$ phases [44-46]. Thus it can be concluded that $\alpha$ phase has the highest hardness compared with other phase's hardness. When the intensity of $\alpha$ phase was decreases, the hardness of Ti-6Al-6Mo alloy will also decrease. According to Figure 6, there is an increase in the hardness value after solution treatment at $950^{\circ} \mathrm{C} / \mathrm{WQ}, 1050^{\circ} \mathrm{C} / \mathrm{WQ}$ and $1050^{\circ} \mathrm{C} / \mathrm{AC}$ temperatures even though $\alpha$ phase intensity decreases, due to the formation of $\beta$-phase precipitate in the $\beta$ and $\alpha$ matrix. The hardness value of Ti-6Al-6Mo alloys at $1050^{\circ} \mathrm{C} / \mathrm{AC}$ solution treatment temperature was higher than that of Ti-6Al-6Mo alloy at $1050^{\circ} \mathrm{C} / \mathrm{WQ}$, around 55,7 HRC. This was caused by increasing in $\alpha$ phase intensity and formation of $\beta$-phase precipitate along grain boundaries. This tend to be uniformly arranged in the $\beta$ retained and $\alpha$ matrix at the solution temperature of $1050^{\circ} \mathrm{C} / \mathrm{AC}$. The precipitates will obstruct the movement of the dislocations. It needs high stress to obtain plastic deformation of the alloy. Thus, the hardness value of the Ti-6Al-6Mo alloy will increase [47].

Figure 7 shows the modulus value of elasticity and phase intensity of Ti-6Al-6Mo after solution treatment. The intensity of $\alpha$ phase in solution treatment $850^{\circ} \mathrm{C} / \mathrm{WQ}$ is the highest among other solution treatment temperature, that is $47,41 \%$. The $\alpha$ and $\omega$ phases have a higher elastic modulus than the $\beta$ phase. According to Hon et al. [48], the $\beta$ phase exhibits a much lower elastic modulus as compared to the $\alpha$ phase, $\mathrm{E} \alpha=1,5 \mathrm{E} \beta$. The elastic modulus of the phases in titanium alloys increase in order $\beta<\alpha^{\prime \prime}<\alpha<\omega$ [48-50]. Meanwhile, in solution treatment $950^{\circ} \mathrm{C} / \mathrm{WQ}$, there was a decrease in elasticity modulus value to 129.26 $\mathrm{GPa}$. Decrease in elastic modulus occurs with the decreasing of $\alpha$ phase intensity in solution treatment $950^{\circ} \mathrm{C} / \mathrm{WQ}$ to $35.89 \%$. The decrease in $\alpha$ phase intensity can be seen in Figure 7 which shows the decrease of peak pattern of $\alpha$ phase diffraction along with the increasing of solution treatment temperature with water cooling medium. The lowest elasticity modulus value was obtained after solution treatment at $1050^{\circ} \mathrm{C} / \mathrm{WQ}$ because it has the lowest phase $\alpha$ intensity among other solution treatment temperature, that is $32,92 \%$. At the same solution 
treatment temperature, which is $1050^{\circ} \mathrm{C}$ using air cooling, the elasticity modulus value increases significantly to $134.41 \mathrm{GPa}$. This phenomenon occurs because the intensity of $\alpha$ phase increases to $44.18 \%$ caused by a slower cooling rate when compared to water cooling. The low cooling rate will provide an opportunity for the $\beta$ phase (when heated) to transform into $\alpha$ phase at room temperature [47].

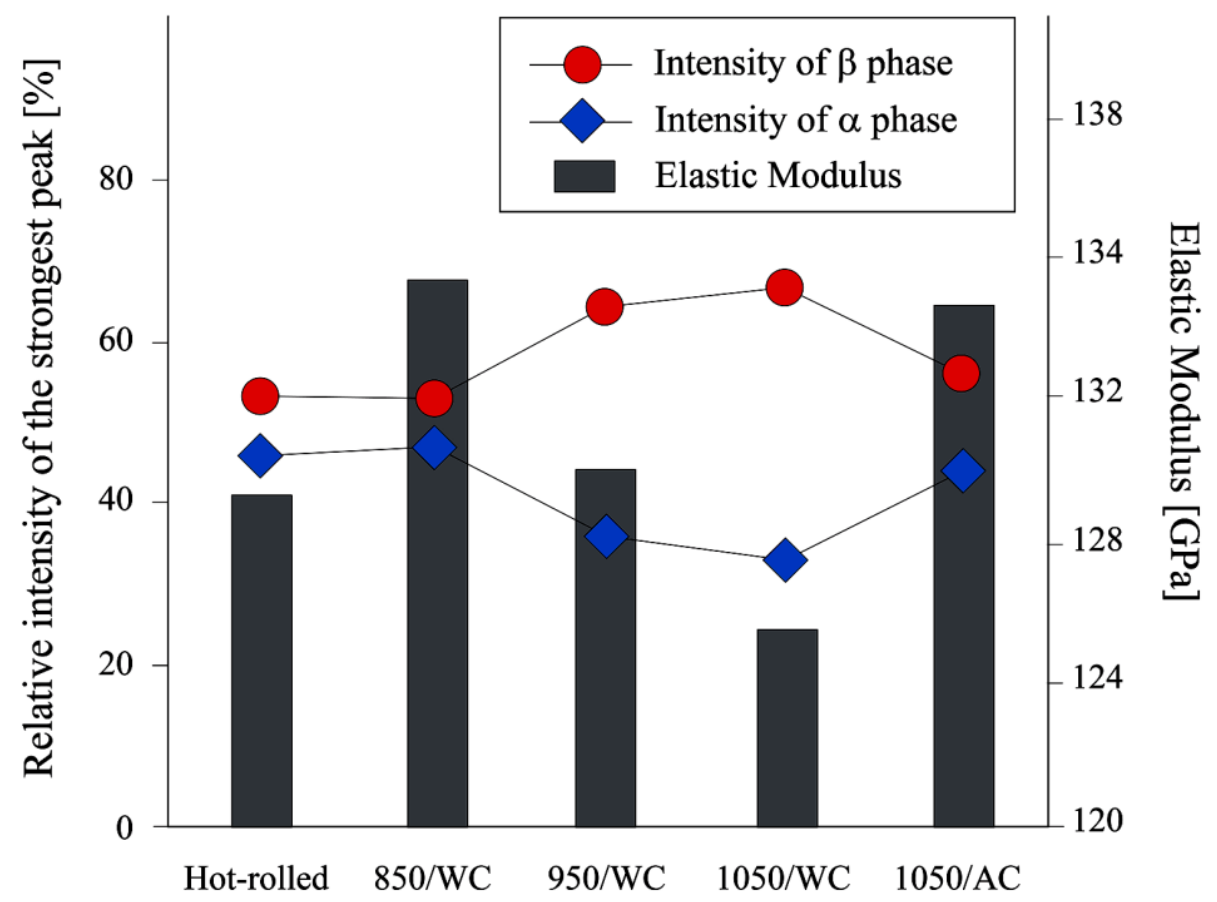

Figure 7. Elastic modulus of Ti-6Al-6Mo alloy before and after solution treatment.

\section{CONCLUSIONS}

Solution treatment solution treatment effected to the microstructure changes. The higher solution temperature approaches $\beta$-transus, reduces the number of $\alpha$-grain granules and increases the grain size $\alpha$ in the $\alpha+\beta$ matrix. While at solution temperature above $\beta$-transus resulted in equiaxed micro structure with $\beta$ retained and $\alpha$ matrix and $\beta$ phase appear as precipitate in grain. The elasticity modulus value decreases with the increasing of solution treatment temperature on the water cooling medium because $\alpha$ phase intensity decreases with the increasing of solution treatment temperature with water cooling medium. Air cooling has a significant effect on increasing alloy hardness after solution treatment because of increasing in $\alpha$ phase intensity and formation of $\beta$-phase precipitate along grain boundaries.

\section{ACKNOWLEDGEMENTS}

The authors thank Indonesia Indonesian Institute of Sciences-LIPI for supplying the To-6Al$6 \mathrm{Mo}$ alloy ingots and research facility used in this study. 


\section{REFERENCES}

[1] Niinomi M. Metallic biomaterials. Journal of Artificial Organs. 2008;11:105-10.

[2] Khan MAR, Rahman MM, Kadirgama K, Noor MM. Prediction of surface roughness of Ti-6Al-4V in electrical discharge machining: a regression model. Journal of Mechanical Engineering and Sciences. 2011;1:16-24.

[3] Zhang Q, Chen J, Tan H, Lin X, Huang W. Microstructure evolution and mechanical properties of laser additive manufactured $\mathrm{Ti}-5 \mathrm{Al}-2 \mathrm{Sn}-2 \mathrm{Zr}-4 \mathrm{Mo}-4 \mathrm{Cr}$ alloy. Transactions of Nonferrous Metals Society of China. 2016;26:2058-66.

[4] Hamdan SH, Said AYM, Biki JR. Surface finish when threading titanium-based alloy under dry machining. Journal of Mechanical Engineering and Sciences. 2014;7:106269.

[5] Ren H, Tian X, Liu D, Liu J, Wang H. Microstructural evolution and mechanical properties of laser melting deposited $\mathrm{Ti}-6.5 \mathrm{Al}-3.5 \mathrm{Mo}-1.5 \mathrm{Zr}-0.3 \mathrm{Si}$ titanium alloy. Transactions of Nonferrous Metals Society of China. 2015;25:1856-64.

[6] Li G, Li J, Tian X, Cheng X, Bei H, Wang H. Microstructure and properties of a novel titanium alloy Ti-6Al-2V-1.5Mo-0.5Zr-0.3Si manufactured by laser additive manufacturing. Materials Science and Engineering: A. 2017;684:233-38.

[7] Zhang Q, Chen J, Zhao Z, Tan H, Xin L, Huang W. Microstructure and anisotropic tensile behavior of laser additive manufactured TC21 titanium alloy. Materials Science and Engineering: A. 2016;673:204-12.

[8] O'Brien B, Stinson J, Carroll W. Initial exploration of Ti-Ta, Ti-Ta-Ir and Ti-Ir alloys: Candidate materials for coronary stents. Acta Biomaterialia. 2008;4:1553-59.

[9] Cho K, Niinomi M, Nakai M, Hieda J, Kawasaki Y. Development of high modulus $\mathrm{TiFeCu}$ alloys for biomedical applications. Material Transactions. 2013;54:574-81.

[10] Alfirano, Mineta S, Namba S, Yoneda T, Ueda K, Narushima T. Heat treatment of ASTM F75 Co-Cr-Mo-C-Si-Mn alloys. Materials Science Forum. 2010;654656,2180-83.

[11] Mad Rosip NI, Ahmad S, Jamaludin KR, Noor FM. Production of 316L stainless steel (SS316L) foam via slurry method. Journal of Mechanical Engineering and Sciences. 2013;5:707-12.

[12] Gil Mur FX, Rodríguez D, Planell JA. Influence of tempering temperature and time on the $\alpha^{\prime}-\mathrm{Ti}-6 \mathrm{Al}-4 \mathrm{~V}$ martensite. Journal of Alloys and Compounds. 1996;234:28789.

[13] Wanying L, Yuanhua L, Yuhai C, Taihe S, Singh A. Effect of different heat treatments on microstructure and mechanical properties of Ti6Al4V titanium alloy. Rare Metal Materials and Engineering. 2017;46:634-39.

[14] Venkatesh BD, Chen DL, Bhole SD. Effect of heat treatment on mechanical properties of Ti-6Al-4V ELI alloy. Materials Science and Engineering A. 2009;506:117-24.

[15] Kumar C, Das M, Paul CP, Bindra KS. Characteristics of fiber laser weldments of two phases $(\alpha+\beta)$ titanium alloy. Journal of Manufacturing Processes. 2018;35:35159.

[16] Niinomi M. Mechanical properties of biomedical titanium alloys. Materials Science and Engineering: A. 1998;243:231-36. 
[17] Kuroda D, Niinomi M, Morinaga M, Kato Y, Yashiro T. Design and mechanical properties of new $\beta$ type titanium alloys for implant materials. Materials Science and Engineering: A. 1998;243:244-49.

[18] Thoemmes A, Ivanov IV, Kashimbetova AA. Comparison of mechanical properties and microstructure of annealed and quenched $\mathrm{Ti}-\mathrm{Nb}$ alloys. Key Engineering Materials. 2018;769:29-34.

[19] Kawahara H. Cytotoxicity of implantable metals and alloys. Bulletin of the Japan Institute of Metals. 1992;31:1033-39.

[20] Kim S, Jung H, Rim HJ, Lee HS, Lee W. Fabrication of reinforced $\alpha+\beta$ titanium alloys by infiltration of Al into porous Ti-V compacts. Journal of Alloys and Compounds. 2018;768:775-81.

[21] Wang J, Qin Z, Xiong F, Wang S, Lu X, Li C. Design and preparation of low-cost $\alpha+\beta$ titanium alloy based on assessment of Ti-Al-Fe-Cr system. Materials Science and Engineering: A. 2018;73:63-69.

[22] Jiang B, Emura S, Tsuchiya K. Microstructural evolution and its effect on the mechanical behavior of Ti-5Al-5Mo-5V-3Cr alloy during aging. Materials Science and Engineering: A. 2018;731:239-48.

[23] Widu F, Drescher D, Junker R, Bourauel C. Corrosion and biocompatibility of orthodontic wires. Journal of Materials Science Materials in Medicine. 1999;10:27581.

[24] Shi Y, Zhang G, Li M, Guo D, Zhang Z, Wei B, Li J, Zhang X. Effect of heat treatment on the microstructure and tensile properties of deformed $\alpha / \beta \mathrm{Ti}-47 \mathrm{Zr}-5 \mathrm{Al}-$ 3V alloy. Journal of Alloys and Compounds. 2016;665:1-6.

[25] Ji X, Emura S, Liu T, Suzuta K, Min X, Tsuchiya K. Effect of oxygen addition on microstructures and mechanical properties of Ti-7.5 Mo alloy. Journal of Alloys and Compounds. 2018;737:221-29.

[26] Schmoelzer T, Mayer S, Haupt F, Zickler GA, Sailer C, Lottermoser L, Güther V, Liss KD, Clemens H. Phase transition and ordering temperatures of TiAl-Mo alloys investigated by in-situ diffraction experiments. Materials Science Forum. 2010;654656:456.

[27] Lu Y, Yamada J, Nakamura J, Yoshimi K, Kato H. Effect of B2-ordered phase on the deformation behavior of Ti-Mo-Al alloys at elevated temperature. Journal of Alloys and Compounds. 2017;696: 130-35.

[28] Wei Z, Peng G, Yongqing Z, Shewei X, Qian L, Jun C, Shiyuan Z, Chaowen H. Evolution of primary $\alpha$ phase morphology and mechanical properties of a novel highstrength titanium alloy during heat treatment. Rare Metal Materials and Engineering. 2017;46:2852-56.

[29] Davari D, Rostami Abbasi SM. Effects of annealing temperature and quenching medium on microstructure, mechanical properties as well as fatigue behavior of Ti6Al-4V alloy. Materials Science and Engineering: A. 2017;683:1-8.

[30] Galarraga H, Warren RJ, DA Lados, Dehoff RR, Kirk MM, Nandwan P. Effects of heat treatments on microstructure and properties of Ti-6Al-4V ELI alloy fabricated by electron beam melting (EBM). Materials Science and Engineering: A. 2017;685:417-28. 
[31] Zhao C, Zhang X, Cao P. Mechanical and electrochemical characterization of Ti$12 \mathrm{Mo}-5 \mathrm{Zr}$ alloy for biomedical application. Journal of Alloys and Compounds. 2011;509:8235-38.

[32] Mohammed MT, Khan ZA, Siddiquee AN. Beta titanium alloys: The lowest elastic modulus for biomedical applications: A review. International Journal of Chemical, Molecular, Nuclear, Materials and Metallurgical Engineering. 2014;8:788-93.

[33] Li CL, Ye WJ, Mi XJ, Hui SX, Lee DG, Lee YT. Development of low cost and low elastic modulus of Ti-Al-Mo-Fe alloys for automotive applications. Key Engineering Materials. 2013;551:114-17.

[34] Borradaile JB, Jeal RH. Mechanical properties of titanium alloys. Warrendale: Metallurgical society of AIME. 1980;141:1-3.

[35] Patil S, Kekade S, Phapale K, Jadhav S, Powar A, Supare A, Singh R. Effect of $\alpha$ and $\beta$ phase volume fraction on machining characteristics of titanium alloy Ti6Al4V. Procedia Manufacturing. 2016;6:63-70.

[36] Turichin GA, Klimova-Korsmik OG, Gushchina MO, Shalnova SA, Korsmik RS, Cheverikin VV, Tataru AS. Features of structure formation in $\alpha+\beta$ titanium alloys. Procedia CIRP. 2018;74:188-91.

[37] Mineta S, Alfirano, Namba S, Yoneda T, Ueda K, Narushima T. Phase and morphology of carbides in ASTM F75 Co-Cr-Mo-C alloys formed at 1473 to 1623 K. Materials Science Forum. 2010;654-656,2176-79.

[38] Jiang B, Emura S, Tsuchiya K. Microstructural evolution and its effect on the mechanical behavior of Ti-5Al-5Mo-5V-3Cr alloy during aging. Materials Science Engineering A. 2018;731:239-48.

[39] Yilmazer H, Niinomi M, Cho K, Nakai M, Hieda J, Sato S, Todaka Y. Microstructural evolution of precipitation-hardened $\beta$-type titanium alloy through high-pressure torsion. Acta Materialia. 2014;80:172-182.

[40] Abdulsalam KS, Alzubaydi TL, Ajeel SA. Influence of heat treatment conditions on microstructure of Ti- 6Al-7Nb alloy as used surgical implant materials. Engineering and Technology Journal. 2007;25:431-442.

[41] Foul A, Aranas Jr. C, Guo B, Jonas JJ. Dynamic transformation of alpha to beta at temperatures below the beta-transus. Materials Science and Engineering: A. 2018;722:156-59.

[42] Majumdar P, Singh SB, Chakraborty M. Elastic modulus of biomedical titanium alloys by nano-indentation and ultrasonic techniques - A comparative study. Materials Science and Engineering A. 2008;489:419-25.

[43] Lütjering G, Williams JC. Titanium. Springer. 2003.

[44] Ho WF, Ju CP, Lin JHC. Structure and properties of cast binary Ti-Mo alloys. Biomaterials. 1999;20:2115-22.

[45] Mantri SA, Choudhuri D, Alam T, Viswanathan GB, Sosa JM, Fraser HL, Banerjee $\mathrm{R}$. Tuning the scale of $\alpha$ precipitates in $\beta$-titanium alloys for achieving high strength. Scripta Materialia. 2018;154, 139-44.

[46] Ji Z, Chen Y, Qiang Y, Shen C, Li H. Effect of deformation of constituent phases on mechanical properties of Ti-6.5Al-3.5Mo-1.5Zr-0.3Si titanium alloy. Materials Science and Engineering: A. 2018;723:29-37. 
[47] Lai MJ, Li T, Raabe D. $\omega$ phase acts as a switch between dislocation channeling and joint twinning- and transformation-induced plasticity in a metastable $\beta$ titanium alloy. Acta Materialia. 2018;151:67-77.

[48] Hon YH, Wang JY, Pan YN. Composition/phase structure properties of titaniumniobium alloys. Materials Transaction. 2003;44:2384-90.

[49] Hao YL, Niinomi M, Kuroda D, Fukunaga F, Zhou YL, Yang R, Suzuki A. Young's modulus and mechanical properties of Ti-29Nb-13Ta-4.6Zr in relation to $\alpha$ " martensite. Metallurgical and Materials Transactions A. 2002;33:3137-44.

[50] Banerjee R, Nag S, Fraser HL. A novel combinatorial approach to the development of beta titanium alloys for orthopedic implants. Materials Science and Engineering: C. $2005 ; 25: 282-89$. 